\title{
Dietary patterns and physical inactivity, two contributing factors to the double burden of malnutrition among adults in Burkina Faso, West Africa
}

\author{
Augustin N. Zeba ${ }^{1,2}$, Hélène F. Delisle ${ }^{1}$ and Genevieve Renier ${ }^{3}$ \\ ${ }^{1}$ Département de Nutrition, Faculté de Médecine, Université de Montréal, C.P. 6128 succ. Centre-ville, Montréal, QC, Canada H3C $3 J 7$ \\ ${ }^{2}$ Institut de Recherche en Sciences de la Santé/Direction Régionale de l'Ouest (IRSS/DRO), 01 BP 545 Bobo Dioulasso 01, Burkina Faso \\ ${ }^{3}$ Centre Hospitalier Universitaire de Montréal, Département de Médecine, Université de Montréal, 1560 Sherbrooke East, Montréal, QC, Canada \\ H2L 4 M1
}

(Received 17 April 2012 - Final revision received 19 October 2012 - Accepted 4 December 2012)

Journal of Nutritional Science (2014), vol. 3, e50, page 1 of 14

doi:10.1017/jns.2014.11

Abstract

A population-based cross-sectional study was carried out in the northern neighbourhoods of Ouagadougou (Burkina Faso), to examine the relationship of nutritional deficiencies and cardiometabolic risk factors (CMRF) with lifestyle in adults. We randomly selected 330 households stratified by income tertile. In each income stratum, 110 individuals aged 25-60 years and having lived in Ouagadougou for at least 6 months were randomly selected. We performed anthropometric, dietary intake and physical activity measurements, and blood sample collection. Cluster analysis of dietary intake identified two dietary patterns: 'urban' (29\% of subjects) and 'traditional' (71\%). The 'urban' cluster exhibited a higher intake of fat and sugar, whereas a higher intake of plant protein, complex carbohydrate and fibre was observed in the 'traditional' pattern. Female sex, low income and lack of education were associated with the 'traditional' cluster, as well as Fe and vitamin A deficiency. CMRF prevalence (abdominal obesity, hypertension, hyperglycaemia, dyslipidaemia) was similar in both clusters. Subjects in the 'traditional' cluster spent more time in physical activity and had less sedentary time than those in the 'urban' cluster. 'Traditional' dietary pattern, low income, female sex and sedentary time were significant contributing factors to the double burden of malnutrition. The rapid nutrition transition is reflected in this co-occurrence of CMRF and nutritional deficiencies. This stresses the need for prevention strategies addressing both ends of the nutrition spectrum.

Key words: Dietary patterns: Physical activity: Micronutrient deficiencies: Cardiometabolic risk factors: Double burden of malnutrition: Adults: Burkina Faso

Risk factors for non-communicable diseases (NCD), including cardiometabolic risk factors (CMRF) ${ }^{(1)}$ and the metabolic syndrome (MetS), are increasing worldwide and even more rapidly in developing countries ${ }^{(2)}$. It is widely accepted that CMRF are becoming the leading contributors to the burden of disease, death and disability over the world, and that mortality from NCD is higher and occurs at a younger age in developing than developed countries ${ }^{(2,3)}$. Evidence suggests that the nutrition transition ${ }^{(4)}$, with progressive shifts of diet and lifestyle toward Western patterns, plays a crucial role in the increased prevalence of $\mathrm{CMRF}^{(1)}$ in developing countries. Indeed, there is convincing evidence linking high intake of energydense foods and saturated fat, low intake of fruits and vegetables, and sedentary lifestyle with $\mathrm{CMRF}^{(5)}$. The inverse association between physical activity and obesity, blood pressure, insulin sensitivity and lipid profiles is well established ${ }^{(6)}$. Conversely, a positive relationship between sedentary lifestyle and number of $\mathrm{CMRF}^{(7)}$ has been demonstrated, with WHO estimates suggesting that almost two million deaths per year worldwide are attributable to physical inactivity ${ }^{(8)}$.

Abbreviations: \%BF, percentage body fat; CMRF, cardiometabolic risk factors; HDL-C, HDL-cholesterol; HOMA, homeostasis model assessment; LDL-C, LDL-cholesterol; MET, metabolic equivalent of tasks; MetS, metabolic syndrome; NCD, non-communicable diseases; WC, waist circumference.

* Corresponding author: Augustin Nawidimbasba Zeba, fax +226 209748 68, email nawidzeb@yahoo.fr 
While CMRF are escalating in developing countries, overall and micronutrient malnutrition remains highly prevalent, even among adults in several instances. Available data from sub-Saharan Africa have reported that $18 \cdot 5,57 \cdot 1$ and $20 \%$ of women exhibit vitamin A deficiency, anaemia and underweight, respectively ${ }^{(9,10)}$. In the adult population of Ouagadougou, we previously reported a high prevalence rate of overweight/obesity (24.2\%), abdominal obesity (12.5\%), hypertension $(21.9 \%)$, hyperglycaemia $(22.3 \%)$ and low HDL-cholesterol (HDL-C) (30\%), with vitamin $\mathrm{A}$ and $\mathrm{Fe}$ deficiencies and anaemia being observed in 12.7, 15.4 and $25.5 \%$ of subjects, respectively, predominantly in women compared with men ${ }^{(11)}$. It has been proposed that low consumption of meat, fish or poultry, especially in poor individuals, is associated with the risk of Fe depletion ${ }^{(12-14)}$ which is usually aggregated with other micronutrient deficiencies ${ }^{(15)}$. It is further argued that poverty could favour diets with adequate energy to meet or exceed energy requirements, while at the same time lacking dietary quality needed to prevent micronutrient deficiencies ${ }^{(16,17)}$.

In order to curb the epidemic of CMRF, the UN member states have endorsed, in the High-level Meeting on NCD in 2011, a solid commitment to implement or reinforce programmes to improve populations' diet and physical activity level, and reduce alcohol consumption ${ }^{(18)}$. However, this concern for the NCD epidemic should not exclude the issue of nutritional deficiencies, as there is mounting evidence that NCD and undernutrition are linked ${ }^{(19,20)}$.

A prerequisite for such programmes is the existence of valid information on population-specific dietary and physical activity patterns, as well as the extent of their association with both CMRF and nutritional deficiencies. Such data are scarce in spite of their relevance in sub-Saharan Africa. The double burden of undernutrition and CMRF has primarily focused on the co-occurrence of maternal obesity and child undernutrition in the same households ${ }^{(21,22)}$. As part of a larger project on the nutrition transition and the double burden of under- and overnutrition in West African countries ${ }^{(23)}$, the present crosssectional study in Ouagadougou was designed to document CMRF and nutritional deficiencies in adults. We hypothesised that a sedentary lifestyle and a more 'modern' diet are associated in an urban setting with both CMRF and micronutrient deficiencies, while controlling for socio-economic factors, featuring the double burden of malnutrition. The present paper reports on the contribution of physical activity and dietary pattern to both CMRF and nutritional deficiencies.

\section{Methods}

\section{Population and sample}

The study was carried out in 2010 in the northern part of Ouagadougou where a population observatory has been in operation since 2008, with periodic collection of socioeconomic, sociodemographic and health data in a population sample of 80000 individuals. This part of the capital city is a vulnerable area on socio-economic and health grounds according to data from national and international institutions ${ }^{(24)}$. The study sample of 330 subjects aged 25-60 years and stratified by income was selected using the observatory database. The availability of data in this part of Ouagadougou such as household identification, socioeconomic and demographic data argued for the present study location. The database included 13021 households with at least one individual between 25 and 60 years of age. A proxy of household income was derived using principal component analysis, with twelve discriminatory household asset variables (ownership of house, telephone, television, DVD, fridge, motorbike, car, type of household toilet, electricity, type of cooking fuel, and type of floor, roof and walls). Households were split into tertiles of this income proxy. For each tertile, 110 households were randomly selected, with fifty additional subjects as alternates. Only one subject per household was enrolled.

Eligible participants were Burkinabè-born adults aged 25 to 60 years old who had been living in Ouagadougou for at least 6 months and who did not expect to move until the end of the study. Subjects with prior hypertension or diabetes were not excluded from the study. Pregnant or lactating women, as well as physically and mentally disabled subjects, were excluded.

Sample size was determined based on the following information. Previous studies have reported a prevalence of overweight/obesity of $33 \%{ }^{(25)}$, and a limited access to micronutrient-rich food in $65.6 \%$ of households in Ouagadougou ${ }^{(26,27)}$, suggesting an estimated $21.5 \%$ of overweight/obese individuals at risk of micronutrient deficiency. We hypothesised that at least half of them (overall prevalence of $10 \%$ ) would show the co-occurrence of overweight/obesity and at least one micronutrient deficiency. A sample size of 300 subjects aged 25 to 60 years was deemed adequate for assessing the prevalence of the double burden of malnutrition with precision of $3 \%$, statistical power of $80 \%$, a CI of $95 \%$ and an $\alpha$ error of $<0 \cdot 05$, using the software Power Analysis and Sample Size (PASS) supplied by NCSS. The size of the sample was increased by $10 \%$ up to 330 , to provide for refusals, missing subjects and incomplete datasets.

\section{Data collection}

The field team consisted of an MD (A. N. Z.), an experienced laboratory technician and two research assistants trained by the first author (A. N. Z.). Following a pre-test of the questionnaire and after obtaining participants' informed consent, personal interviews provided information on their age, parity, education level, psychosocial factors, and diet and lifestyle patterns. Anthropometric and clinical data as well as blood samples were also collected. The interviews were repeated $6-8 \mathrm{~d}$ later for an additional $24 \mathrm{~h}$ recall of dietary intake and physical (in)activity.

\section{Anthropometrics and body composition}

Body weight was measured to the nearest $100 \mathrm{~g}$ with subjects in light clothing and without shoes, using a portable electronic scale of $150 \mathrm{~kg}$ capacity (Seca 803 Clara Scale). Height was 
measured to the nearest $0.5 \mathrm{~cm}$ using a portable locally built stadiometer, with the subject standing upright on a flat surface without shoes, and the back of the heels and the occiput against the stadiometer. Waist circumference (WC) was measured to the nearest $0.1 \mathrm{~cm}$ with a flexible non-stretch and tension-regulated steel tape (Gulick measuring tape $\odot$; Creative Health Products, Inc.) at the midpoint between the lowest rib and the iliac crest while subjects were standing and breathing normally ${ }^{(28)}$. The average of two separate measures of body weight, height and WC was used in the analyses. BMI was calculated as weight $(\mathrm{kg})$ divided by height $\left(\mathrm{m}^{2}\right)$. BMI was categorised as follows: underweight: $<18 \cdot 5$; normal: $18 \cdot 5-$ 24.9; overweight, 25-29.9; obese, $\geq 30 \mathrm{~kg} / \mathrm{m}^{2(29)}$. Abdominal obesity was defined as a $W C \geq 94 \mathrm{~cm}$ for men and $\geq 80 \mathrm{~cm}$ for women ${ }^{(30)}$. Bioelectrical impedance analysis (BIA) was performed to measure body composition (RJL Systems). For BIA measurements, subjects had to be in the fasting state for at least $12 \mathrm{~h}$, had not engaged in vigorous work or physical activity during the last $24 \mathrm{~h}$ and had abstained from alcohol for the previous $48 \mathrm{~h}$. The individual lay on a non-conductive surface with a minimum of clothing before the electrodes were placed on the hand and foot of the same body side (left or right). We computed the percentage body fat $(\% \mathrm{BF})$ using the prediction equation for fat-free mass suggested by Sun et al. for several race/ethnicity subjects ${ }^{(31)}$. High body fat was defined as $\% \mathrm{BF}>25 \%$ in men, and $\% \mathrm{BF}>33 \%$ in women, as suggested for both black and white subjects ${ }^{(32)}$.

\section{Blood pressure}

Blood pressure was measured by A. N. Z. with a calibrated anaeroid sphygmomanometer on the right arm of seated subjects after a minimum of $10 \mathrm{~min}$ rest. Systolic and diastolic blood pressures were measured twice with an interval of 10 min between the first and the second measurements. Mean of the two readings was used in the analyses. High blood pressure for subjects without prior diagnosis of hypertension was defined as systolic blood pressure $\geq 130 \mathrm{mmHg}$ or diastolic blood pressure $\geq 85 \mathrm{mmHg}^{(30)}$.

\section{Blood sampling and laboratory measures}

Venous blood samples were drawn after an overnight fast of at least $12 \mathrm{~h}$, in $10 \mathrm{ml}$ EDTA and dry tubes for plasma and serum collection, respectively. Blood samples were immediately stored in cold boxes and brought to the laboratory within 2 h. Samples were centrifuged at $3000 \mathrm{rpm}$ for $10 \mathrm{~min}$, sampled in cryotubes and frozen at $-32^{\circ} \mathrm{C}$. Fasting glucose was immediately determined from plasma samples using the glucose oxidase method at the Medical Analysis Laboratory of the University of Ouagadougou. Hyperglycaemia was defined as fasting plasma glucose $>5.6 \mathrm{mmol} / 1$ for subjects without prior diagnosis of diabetes ${ }^{(30)}$. Plasma concentrations of HDL-C, LDL-cholesterol (LDL-C) and TAG were determined by enzymic methods. Cut-offs for low HDL-C were $<1.0 \mathrm{mmol} / 1$ for men and $<1.3 \mathrm{mmol} / 1$ for women. The cutoff for high plasma LDL-C was $>3.37 \mathrm{mmol} / \mathrm{l}$. Hypertriacylglycerolaemia was defined as plasma TAG concentration $>1.7 \mathrm{mmol} / \mathrm{l}^{(30,33)}$. The ratio of total cholesterol (TC) to HDL-C (TC:HDL-C) was computed and a value $>5$ for men and $>4$ for women was defined as high ${ }^{(34)}$. Serum insulin concentration was measured by RIA (Cisbio Bioassays) and the homeostasis model assessment (HOMA) equation ((fasting glycaemia $\times$ serum insulin)/22.5) was used as an index of insulin resistance. Insulin resistance was defined as a HOMA $\geq 75$ th centile in the whole study population ${ }^{(35)}$. Serum retinol was measured using HPLC at the Laboratoire de Chimie Analytique et Toxicologie (LACATOX) de l'Université de Ouagadougou, Burkina Faso, with serum retinol level $<0.7 \mu \mathrm{mol} / 1$ being indicative of vitamin A deficiency ${ }^{(36)}$. Plasma ferritin level was measured using chemiluminescence with a cut-off of $<15 \mu \mathrm{g} / \mathrm{l}$ for Fe depletion. $\mathrm{Hb}$ was directly measured in the field from a drop of whole blood using HemoCue ${ }^{\circledR}$ (Hemocue HB 201+). Anaemia was defined as $\mathrm{Hb}<120 \mathrm{~g} / 1$ in women and $<130$ $\mathrm{g} / \mathrm{l}$ in $\mathrm{men}^{(37)}$. Insulin, ferritin and blood lipid determinations were carried out at the Laboratoire de pathologie cellulaire et moléculaire en nutrition, Faculté de Medecine, Nancy-Université, France.

\section{Nutritional deficiencies and cardiometabolic risk markers}

Three nutritional deficiency indicators were considered when assessing the double burden of malnutrition: underweight, $\mathrm{Fe}$ depletion and vitamin A deficiency. Individual CMRF were the following, for a maximum count of four: overweight or overall obesity or abdominal obesity; hypertension or under medical treatment; hyperglycaemia or insulin resistance or diagnosed diabetes; and dyslipidaemia (high LDL-C or low HDL-C or hypertriacylglycerolaemia or high TC:HDL-C). The MetS was defined as the clustering within a subject of at least three of the following CMRF: abdominal obesity, hyperglycaemia or treated diabetes, hypertriacylglycerolaemia, low HDL-C, and high blood pressure or treated hypertension ${ }^{(30)}$.

\section{Dietary assessment, dietary patterns and micronutrient adequacy ratio}

Quantitative dietary intake was assessed with two nonconsecutive $24 \mathrm{~h}$ recalls carried out by two trained research assistants, using the multiple-pass method for memory bias minimisation ${ }^{(38)}$. The face-to-face recalls were performed with each participant, separated by 6 or $8 \mathrm{~d}$. To estimate food portion sizes, previously calibrated local kitchen utensils (spoons, glasses, cups, bowls, plates, etc.) were used as visual aids. We computed energy and nutrient intakes using as primary source of data the food composition table developed in the neighbouring country of Mali ${ }^{(39)}$. Usual nutrient intake was estimated after adjusting for differences between interviewers, and number of days between the recalls, using Software for Intake Distribution Estimation (C-SIDE; Iowa State University) ${ }^{(40)}$.

A total number of sixteen food groups (local cereals, imported cereals, legumes, oilseeds, tubers, red meat, white meat, fish, eggs, milk and milk products, traditional green 
leafy vegetables, other vegetables, fruits, local sweetened juices, soft drinks and alcoholic beverages) were defined in order to capture 'local' and 'imported' food and beverage items. Dietary patterns were generated using K-means cluster analysis ${ }^{(41)}$, based on standardised daily intakes (Z-scores) of food groups expressed in $\mathrm{g}$ per $4184 \mathrm{~kJ}(1000 \mathrm{kcal})^{(42)}$. Two to four cluster solutions were examined to evaluate which set of clusters was meaningful and statistically relevant to define dietary patterns.

The adequacy of intake of eleven micronutrients (vitamin $\mathrm{A}$, thiamin, riboflavin, vitamins $\mathrm{B}_{6}$ and $\mathrm{B}_{12}$, niacin, folate, vitamin $\mathrm{C}, \mathrm{Ca}, \mathrm{Fe}$ and $\mathrm{Zn}$ ) was checked against the recommended dietary intake for age and sex ${ }^{(43)}$. The percentage adequacy was obtained by dividing the intake of a given nutrient by the recommended intake multiplied by 100 and the mean percentage adequacy was computed for each micronutrient. The 'bioavailability of $5 \%$ ' and 'low bioavailability' for $\mathrm{Fe}$ and $\mathrm{Zn}$, respectively, were used given the high local phytate load in the diet. We computed micronutrient density (per $4184 \mathrm{~kJ}$ $(1000 \mathrm{kcal}))$ for each dietary pattern.

\section{Physical activity}

Physical activity was assessed through two non-consecutives $24 \mathrm{~h}$ recalls ${ }^{(44)}$ by two trained interviewers. Subjects were asked to describe all types of physical activity they performed during the preceding $24 \mathrm{~h}$, classified as time for sleep (during the day and in the night), leisure, transportation and main occupation (employment or housework). Activities for work, transportation and leisure were recorded. These activities were then broken down in two categories according to their intensity according to the compendium of physical activities ${ }^{(45)}$ as follows: activities $<3 \cdot 0$ metabolic equivalent of tasks (MET) and activities $\geq 3.0 \mathrm{MET}$. Time spent in each category of activity was recorded in minutes and was expressed as mean number of hours per d. We defined as 'sedentary time' time that was spent in activities $<3.0 \mathrm{MET}$, and as 'active time' time that was spent in activities $\geq 3.0 \mathrm{MET}$ and the total daily 'sedentary' and 'active' hours were computed.

\section{Statistical analyses}

Data were analysed using SPSS version 18.0 (IBM). Comparisons between women and men, and between dietary clusters, were performed using Student's $t$ test, or the one-way ANOVA test for means with the Bonferroni post hoc test for multiple comparisons, and $\chi^{2}$ for proportions. Multiple linear regression models were constructed to analyse the relationship between sociodemographic factors, physical activity and dietary patterns and micronutrient deficiencies and CMRF. A binary logistic regression analysis was performed to assess the odds of having micronutrient deficiencies or CMRF according to 'urban' or 'traditional' dietary pattern. A multinomial logistic regression with a main-effects model was performed to assess the odds of presenting the double burden of malnutrition phenotypes according to physical activity and dietary patterns while controlling for confounding factors. The level of statistical significance was a $P$ value $<0 \cdot 05$.

\section{Ethical considerations}

The present study was conducted according to the guidelines laid down in the Declaration of Helsinki and all procedures involving human subjects were approved by the Ethics Committee of the Faculty of Medicine, University of Montreal, and the Ethics Committee for Health Research of Burkina Faso.

The study objectives were clearly explained to participants, selected household heads and local authorities. A written informed consent was obtained from each study subject before enrolment. Participants were informed of their results on blood pressure and glycaemia, and those with abnormal values were referred for diagnosis and treatment, with support by the research project.

\section{Results}

A total of 310 subjects (51.9\% women) completed the study, giving a response rate of $94 \%$. Mean age of the population under study was 36.4 (SD 9.1) years. Women were less educated than men $(P=0.05)$ and showed lower serum retinol and ferritin, and lower plasma $\mathrm{Hb}$ than men $(P=0.002$, $<0.001$ and $<0.001$, respectively) (Table 1$)$. Women had higher BMI values and higher body fat than men (both $P<$ $0 \cdot 001)$ and their mean HDL-C values were significantly higher than men $(P=0 \cdot 006)$. Mean $\mathrm{WC}$ and other biochemical values were similar in men and women.

\section{Physical activity and dietary patterns}

As shown in Table 2, active time (h per d) was significantly lower than sedentary time $(P<0 \cdot 001)$ in the overall sample. Compared with women, men had less sedentary time, whereas both men and women had similar active times. Active time significantly decreased from low to high income level while sedentary time was significantly higher in the high-income group. More-educated subjects exhibited significantly less active time than uneducated, whereas sedentary time was not different according to education level.

The three-cluster solution of dietary patterns was retained but two patterns remained after excluding three subjects in the third cluster. Table 3 presents food group consumption (per $4184 \mathrm{~kJ}$ $(1000 \mathrm{kcal}))$ according to dietary patterns. The 'urban' diet cluster (29\% of subjects) was characterised by a significantly higher intake of imported cereals, oilseeds, red meat, eggs, milk and milk products, vegetables other than greens, fruits, local sweetened juices (ginger, tamarind or sweet pea juices) and soft drinks, whereas the 'traditional' diet cluster ( $71 \%$ of subjects) was characterised by a higher intake of local cereals, legumes and traditional green leafy vegetables. As shown in Table 2, female sex, low-income and no-education subjects were significantly aggregated in the 'traditional' diet cluster $(P=0 \cdot 004$, 0.002 and $<0.001$, respectively), whereas men, higher-income and more-educated subjects were significantly more represented in the 'urban' diet cluster.

Micronutrient density (intake per $4184 \mathrm{~kJ}(1000 \mathrm{kcal}))$ was significantly higher in the 'urban' than 'traditional' diet when considering riboflavin, vitamin $\mathrm{B}_{6}$, vitamin $\mathrm{B}_{12}$, niacin and vitamin $\mathrm{C}$ 
Table 1. Sociodemographic characteristics and health related markers of the study subjects* (Mean values and standard deviations or percentages and $95 \%$ confidence intervals)

\begin{tabular}{|c|c|c|c|c|c|c|c|}
\hline & \multicolumn{2}{|c|}{ All $(n 310)$} & \multicolumn{2}{|c|}{ Women ( $n$ 161) } & \multicolumn{2}{|c|}{ Men ( $n$ 149) } & \multirow[b]{2}{*}{$P \dagger$} \\
\hline & Mean & SD & Mean & SD & Mean & SD & \\
\hline Age (years) & $36 \cdot 4$ & $9 \cdot 1$ & $35 \cdot 7$ & $8 \cdot 9$ & $37 \cdot 1$ & 9.2 & 0.161 \\
\hline \multicolumn{8}{|l|}{ Formal education } \\
\hline None & & & & & & & 0.061 \\
\hline$\%$ & \multicolumn{2}{|c|}{$40 \cdot 3$} & \multicolumn{2}{|c|}{$45 \cdot 3$} & \multicolumn{2}{|c|}{34.9} & \\
\hline $95 \% \mathrm{Cl}$ & \multicolumn{2}{|c|}{$34.8-45.8$} & \multicolumn{2}{|c|}{$37.6-53.0$} & \multicolumn{2}{|c|}{$27 \cdot 3-42 \cdot 5$} & \\
\hline Elementary school & & & & & & & 0.913 \\
\hline$\%$ & \multicolumn{2}{|c|}{$19 \cdot 0$} & \multicolumn{2}{|c|}{$19 \cdot 3$} & \multicolumn{2}{|c|}{$18 \cdot 8$} & \\
\hline $95 \% \mathrm{Cl}$ & \multicolumn{2}{|c|}{$14.6-23.4$} & \multicolumn{2}{|c|}{$13 \cdot 2-25 \cdot 4$} & \multicolumn{2}{|c|}{$12 \cdot 5-25 \cdot 1$} & \\
\hline High school and above & & & & & & & 0.050 \\
\hline$\%$ & \multicolumn{2}{|c|}{$40 \cdot 6$} & \multicolumn{2}{|c|}{35.4} & \multicolumn{2}{|c|}{$46 \cdot 3$} & \\
\hline $95 \% \mathrm{Cl}$ & \multicolumn{2}{|c|}{$35 \cdot 1-46 \cdot 1$} & \multicolumn{2}{|c|}{$28 \cdot 0-42 \cdot 8$} & \multicolumn{2}{|c|}{$38 \cdot 3-54 \cdot 3$} & \\
\hline $\mathrm{Hb}(\mathrm{g} / \mathrm{l})$ & 134 & 19 & 124 & 14 & 145 & 18 & $<0.001$ \\
\hline Ferritin $(\mu \mathrm{g} / \mathrm{l})$ & $66 \cdot 6$ & $70 \cdot 9$ & 43.4 & $50 \cdot 8$ & 91.7 & $80 \cdot 6$ & $<0.001$ \\
\hline Retinol $(\mu \mathrm{mol} / \mathrm{l})$ & $1 \cdot 2$ & 0.5 & 1.1 & 0.5 & $1 \cdot 3$ & 0.5 & 0.002 \\
\hline BMI $\left(\mathrm{kg} / \mathrm{m}^{2}\right)$ & $22 \cdot 7$ & $4 \cdot 2$ & 23.7 & $4 \cdot 8$ & $21 \cdot 7$ & 3.1 & $<0.001$ \\
\hline WC $(\mathrm{cm})$ & $78 \cdot 4$ & $10 \cdot 2$ & $79 \cdot 2$ & 11.5 & $77 \cdot 4$ & 8.7 & 0.127 \\
\hline Body fat (kg) & $15 \cdot 9$ & $13 \cdot 2$ & $19 \cdot 9$ & $16 \cdot 6$ & $11 \cdot 6$ & 5.9 & $<0.001$ \\
\hline $\mathrm{SBP}(\mathrm{mmHg})$ & $12 \cdot 1$ & 1.6 & $12 \cdot 1$ & 1.6 & $12 \cdot 3$ & 1.6 & 0.392 \\
\hline $\mathrm{DBP}(\mathrm{mmHg})$ & 7.5 & 0.8 & 7.5 & 0.8 & 7.5 & 0.9 & 0.763 \\
\hline Glycaemia (mmol/l) & 5.4 & 1.6 & 5.4 & 1.7 & 5.4 & 1.6 & 0.754 \\
\hline LDL-C (mmol/l) & $2 \cdot 3$ & 0.8 & $2 \cdot 3$ & 0.8 & $2 \cdot 3$ & 0.7 & 0.573 \\
\hline $\mathrm{HDL}-\mathrm{C}(\mathrm{mmol} / \mathrm{l})$ & $1 \cdot 1$ & 0.3 & $1 \cdot 1$ & 0.3 & 1.0 & 0.2 & 0.006 \\
\hline TC:HDL-C & 3.5 & 0.9 & 3.5 & 0.9 & 3.6 & 0.8 & 0.168 \\
\hline TAG $(\mathrm{mmol} / \mathrm{l})$ & 0.7 & 0.3 & 0.7 & 0.3 & 0.7 & 0.3 & 0.201 \\
\hline HOMA & $5 \cdot 8$ & $6 \cdot 1$ & $5 \cdot 8$ & 4.5 & $5 \cdot 9$ & 7.5 & 0.812 \\
\hline
\end{tabular}

WC, waist circumference; SBP, systolic blood pressure; DBP, diastolic blood pressure; LDL-C, LDL-cholesterol; HDL-C, HDL-cholesterol; TC, total cholesterol; HOMA, homeostasis model assessment.

* Exclusion of eight and two subjects with prior diagnosis of hypertension and diabetes, respectively.

$\dagger$ Significant difference between women and men as determined by Student's $t$ test and $\chi^{2}$ test.

intake. In contrast, folate and Fe density was higher in the 'traditional' diet (Table 4). Mean micronutrient adequacy was under 60 $\%$ of the recommended intake in both dietary pattern groups for vitamin $A$, riboflavin, vitamin $B_{6}$, niacin, folate and $\mathrm{Ca}$. Adequacy of vitamin $B_{12}$ was particularly low (only 19\%) in the 'traditional' diet cluster, compared with $82 \%$ in the 'urban' diet cluster. Similarly, vitamin $\mathrm{C}$ adequacy was significantly lower in the 'traditional' than in the 'urban' cluster $(60 v .78 \%$, respectively; $P<$ 0.001). Thiamin, Fe and Zn adequacy was significantly higher in the 'traditional' diet cluster as compared with the 'urban' one.

Table 2. Physical activity and dietary patterns according to sociodemographic characteristics*

(Mean values and standard deviations or percentages and $95 \%$ confidence intervals)

Daily physical activity by intensity level according to MET $(\mathrm{h} / \mathrm{d})$
Dietary patterns

\begin{tabular}{|c|c|c|c|c|c|c|c|c|c|c|c|}
\hline & & & & & & & \multirow{2}{*}{\multicolumn{4}{|c|}{$\begin{array}{c}\text { 'Traditional' diet } \\
(n 218)\end{array}$}} & \\
\hline & \multicolumn{3}{|c|}{ Active time ( $\geq 3$ MET) } & \multicolumn{3}{|c|}{ Sedentary time $(<3 \mathrm{MET})$} & & & & & \multirow[b]{2}{*}{$P+$} \\
\hline & Mean & SD & $P+$ & Mean & SD & $P+$ & $\%$ & $95 \% \mathrm{Cl}$ & $\%$ & $95 \% \mathrm{Cl}$ & \\
\hline Sample‡ & 4.4 & $2 \cdot 4$ & & 11.5 & 3.1 & & 29.0 & $23 \cdot 9,34 \cdot 1$ & 71.0 & $65 \cdot 9,76 \cdot 1$ & $<0.001$ \\
\hline Women & 4.4 & 1.9 & & $12 \cdot 1$ & $2 \cdot 8$ & & $39 \cdot 3$ & $29.1,49.5$ & 57.3 & $50 \cdot 6,64.0$ & 0.004 \\
\hline Men & 4.3 & $2 \cdot 7$ & 0.653 & $10 \cdot 8$ & 3.4 & $<0.001$ & $60 \cdot 7$ & $50.5,70.9$ & $42 \cdot 7$ & $36 \cdot 0,49 \cdot 4$ & 0.004 \\
\hline Income level & & & & & & & & & & & \\
\hline Low & $5 \cdot 3^{\mathrm{a}}$ & $2 \cdot 7$ & & $10 \cdot 7^{\mathrm{a}}$ & 3.3 & & 19.1 & $11 \cdot 1,27 \cdot 3$ & 41.3 & $34 \cdot 8,47 \cdot 8$ & 0.002 \\
\hline Middle & $4 \cdot 3^{\mathrm{b}}$ & $2 \cdot 2$ & & $11 \cdot 4^{a, b}$ & 3.1 & & $37 \cdot 1$ & $27 \cdot 1,47 \cdot 1$ & $32 \cdot 1$ & $25 \cdot 9,38,3$ & 0.402 \\
\hline High & $3.4^{\mathrm{C}}$ & $\begin{array}{l}2.2 \\
1.6\end{array}$ & $<0.001$ & $12 \cdot 4^{\mathrm{c}}$ & 2.8 & $<0.001$ & 43.8 & $33.5,54 \cdot 1$ & $26 \cdot 6$ & $20 \cdot 7,32 \cdot 5$ & 0.003 \\
\hline Formal education & & & & & & & & & & & \\
\hline None & $4 \cdot 8^{a}$ & $2 \cdot 4$ & & $11 \cdot 1$ & 3.2 & & 24.7 & $15.8,33.6$ & $46 \cdot 8$ & $40 \cdot 2,53 \cdot 4$ & $<0.001$ \\
\hline Elementary school & $4 \cdot 6^{\mathrm{a}, \mathrm{b}}$ & 2.5 & & 11.6 & $3 \cdot 1$ & & $15 \cdot 7$ & $8 \cdot 2,23 \cdot 2$ & $20 \cdot 6$ & $15 \cdot 2,26 \cdot 0$ & 0.321 \\
\hline High school and above & $3 \cdot 8^{\mathrm{b}, \mathrm{c}}$ & $2 \cdot 1$ & 0.002 & 11.7 & 3.0 & 0.251 & 59.6 & $49.4,69.8$ & 32.6 & $26 \cdot 4,38.7$ & $<0.001$ \\
\hline
\end{tabular}

MET, metabolic equivalent of tasks.

a,b,c Values within a column with unlike superscript letters were significantly different (one-way ANOVA).

* Exclusion of three subjects (one female and two males) in a third cluster of dietary patterns.

† Significant difference between groups as determined by Student's $t$ test, $\chi^{2}$ test or one-way ANOVA with the Bonferroni post hoc test for multiple comparisons.

$\ddagger$ For the whole sample, sedentary time was significantly higher than active time $(P<0.001)$ 
Table 3. Food group intakes according to dietary pattern (Mean values and standard deviations)

\begin{tabular}{|c|c|c|c|c|c|c|c|}
\hline \multirow[b]{3}{*}{ Food groups } & \multicolumn{6}{|c|}{ Intake according to dietary pattern (g/4184 kJ (1000 kcal)) } & \multirow[b]{3}{*}{$P^{\star}$} \\
\hline & \multicolumn{2}{|c|}{ Sample ( $n$ 307) } & \multicolumn{2}{|c|}{ 'Urban' diet ( $n$ 92) } & \multicolumn{2}{|c|}{$\begin{array}{l}\text { 'Traditional' diet } \\
\text { (n 218) }\end{array}$} & \\
\hline & Mean & SD & Mean & SD & Mean & SD & \\
\hline Local cereals & 359.2 & $216 \cdot 2$ & 234.6 & $191 \cdot 7$ & $410 \cdot 0$ & 205.0 & $<0.001$ \\
\hline Imported cereals & $90 \cdot 9$ & 83.9 & 155.4 & $96 \cdot 8$ & 64.6 & 61.0 & $<0.001$ \\
\hline Legumes & 95.9 & $112 \cdot 1$ & $52 \cdot 7$ & $96 \cdot 3$ & 113.5 & $113 \cdot 6$ & $<0.001$ \\
\hline Oil seeds & $55 \cdot 4$ & 61.9 & $91 \cdot 1$ & $74 \cdot 1$ & $40 \cdot 8$ & $49 \cdot 4$ & $<0.001$ \\
\hline Tubers & $10 \cdot 7$ & $42 \cdot 6$ & $10 \cdot 4$ & $47 \cdot 4$ & $10 \cdot 9$ & 40.7 & 0.935 \\
\hline Red meat & 11.9 & 37.9 & $34 \cdot 2$ & $64 \cdot 4$ & 2.9 & 10.7 & $<0.001$ \\
\hline White meat & 0.5 & 5.6 & 0.7 & 7.0 & 0.3 & $5 \cdot 0$ & 0.576 \\
\hline Fish & $10 \cdot 7$ & 26.5 & $12 \cdot 2$ & $20 \cdot 2$ & $10 \cdot 1$ & 28.7 & 0.538 \\
\hline Eggs & 0.6 & 4.5 & 1.9 & 8.1 & 0.1 & 0.6 & 0.001 \\
\hline Milk and milk products & 22.9 & 71.9 & $62 \cdot 3$ & 113.6 & $6 \cdot 7$ & 333.9 & $<0.001$ \\
\hline Traditional green leafy vegetables & 59.5 & 74.2 & 37.6 & $72 \cdot 3$ & 68.4 & $73 \cdot 3$ & 0.001 \\
\hline Other vegetables & $20 \cdot 1$ & 51.6 & $50 \cdot 7$ & 81.9 & 7.7 & 22.5 & $<0.001$ \\
\hline Fruits & $10 \cdot 1$ & 33.7 & 28.4 & 53.3 & $2 \cdot 6$ & $16 \cdot 1$ & $<0.001$ \\
\hline Local sweetened juices & $34 \cdot 6$ & $101 \cdot 8$ & $68 \cdot 1$ & $146 \cdot 9$ & $20 \cdot 9$ & $72 \cdot 3$ & $<0.001$ \\
\hline Soft drinks & 1.9 & $15 \cdot 7$ & 6.6 & 28.8 & 0.1 & 1.5 & 0.001 \\
\hline Alcoholic beverages & 25.6 & 114.8 & $12 \cdot 8$ & $60 \cdot 7$ & $30 \cdot 8$ & $130 \cdot 4$ & 0.213 \\
\hline
\end{tabular}

* Significant difference between groups as determined by Student's $t$ test.

The 'urban' diet was characterised by a higher amount and percentage of fat and sugar, whereas the 'traditional' diet was significantly higher in protein (primarily plant protein), carbohydrate and fibre (Table 5). The percentage contribution of protein to total energy was similar. Total energy intake was significantly higher in the 'traditional' diet cluster $(P<$ 0.001). The contribution of sugar to the energy intake for both 'urban' and 'traditional' diets was above the $\mathrm{WHO}^{(46)}$ recommendation for $\mathrm{NCD}$ prevention and significantly higher in the urban diet than in the 'traditional' one. Fibre intake was lower than WHO recommendations in both diet types $^{(46)}$.

\section{Malnutrition and cardiometabolic risk factors according to physical activity and dietary patterns}

Anaemic, Fe-deficient and vitamin A-deficient subjects were more prone to be aggregated in the traditional diet cluster: OR $1.85(95 \%$ CI $1.01,3.43 ; P=0.049)$, OR $3.27(95 \%$ CI $1.33,8.03 ; P=0.009)$ and OR $3.21(95 \%$ CI 1.21, 8.49; $P=0.019)$, respectively. The OR of CMRF were not associated with dietary patterns (Table 6 ), but subjects exhibiting overweight/obesity, abdominal obesity, high \%BF, high glycaemia, high blood pressure, hypertriacylglycerolaemia, MetS, high LDL-C or insulin resistance (high HOMA) had significantly fewer active hours. Sedentary time was also significantly higher in subjects with overweight/obesity, abdominal obesity, high \%BF and the MetS.

The relationship between micronutrient status or CMRF on the one hand, and physical activity and dietary patterns ('urban' $=0$ and 'traditional' =1) on the other hand was tested using two regression models. In the first model (without control variables), the 'urban' dietary pattern was significantly associated with higher $\mathrm{Hb}$ and higher serum ferritin concentrations $\quad(\beta=-0.173$ and $-0.133 ; \quad P<0.05$, respectively) and showed a borderline association with higher serum retinol $(\beta=-0.103 ; P=0.076$ ) (data not shown). Regarding CMRF, the 'urban' pattern was only significantly associated with high HOMA $(\beta=-0.118 ; P=$ 0.047). Active time was significantly and negatively associated with BMI, WC, body fat, systolic and diastolic blood pressure, triacylglycerolaemia and LDL-C, whereas sedentary time was significantly and positively associated with BMI, WC and systolic blood pressure. After controlling for sociodemographic characteristics (Table 7), dietary patterns lost their significant predictive power of $\mathrm{Hb}$ and serum retinol concentration. This model now reveals a positive and significant association of male sex with $\mathrm{Hb}$, ferritin and retinol concentrations, with female sex being associated with lower values. Income level was also positively associated with $\mathrm{Hb}$ and serum retinol concentrations, while sedentary time was negatively associated with serum ferritin level. Controlling for sociodemographic characteristics did not change the significant association of active time with CMRF or between the urban dietary pattern and higher insulin resistance as evidenced by higher HOMA $(\beta=-$ $0 \cdot 105 ; P=0 \cdot 042)$. Age was positively and significantly associated with BMI, WC, systolic and diastolic blood pressure, triacylglycerolaemia and LDL-C level. Female sex was significantly associated with high BMI, WC, high body fat and high HDL-C. Education level was positively associated with BMI while income level was negatively associated with glycaemia.

Taking account of CMRF and nutritional deficiency markers, five phenotypes were identified: phenotype 1 for 'normal' subjects showing neither nutritional deficiencies nor CMRF (11.72\%); phenotype 2 or 'deficient' subjects, exhibiting underweight or micronutrient deficiencies (6.84\%); phenotype 3 for subjects with CMRF, overweight/obesity or other ( $55.40 \%)$; phenotype 4 for the first 'double burden' 
Table 4. Micronutrient density and adequacy ratio according to dietary pattern (Mean values and standard deviations)

Micronutrients (with FAO/WHO recommended intake)
Micronutrient density of the diet (per 4184 kJ (1000 kcal))

\begin{tabular}{|c|c|c|c|c|c|c|c|c|c|c|c|c|}
\hline \multirow{3}{*}{ recommenued intake) } & \multirow{2}{*}{\multicolumn{2}{|c|}{ Total (n 307) }} & \multirow{2}{*}{\multicolumn{2}{|c|}{$\begin{array}{l}\text { Urban diet } \\
\quad(n 89)\end{array}$}} & \multirow{2}{*}{\multicolumn{2}{|c|}{$\begin{array}{l}\text { Traditional diet } \\
\qquad(n 218)\end{array}$}} & \multirow{3}{*}{$P^{\star}$} & \multirow{2}{*}{\multicolumn{2}{|c|}{$\begin{array}{l}\text { Urban diet } \\
\quad(n 89)\end{array}$}} & \multirow{2}{*}{\multicolumn{2}{|c|}{$\begin{array}{l}\text { Traditional } \\
\text { diet }(n 218)\end{array}$}} & \multirow{3}{*}{$P^{*}$} \\
\hline & & & & & & & & & & & & \\
\hline & Mean & SD & Mean & SD & Mean & SD & & Mean & SD & Mean & SD & \\
\hline \multicolumn{13}{|l|}{ Vitamin A ( $\mu g$ RE) } \\
\hline $\begin{array}{l}500 \text { for females } \\
600 \text { for males }\end{array}$ & 73.76 & $46 \cdot 11$ & 69.46 & 38.08 & $75 \cdot 51$ & 48.99 & 0.297 & 26.56 & $19 \cdot 13$ & 31.19 & 19.67 & 0.060 \\
\hline \multicolumn{13}{|l|}{ Thiamin (mg) } \\
\hline $\begin{array}{l}1 \cdot 1 \text { for females } \\
1.2 \text { for males }\end{array}$ & 0.42 & 0.09 & 0.44 & 0.07 & 0.42 & 0.09 & 0.140 & 78.05 & $19 \cdot 21$ & 84.45 & $22 \cdot 74$ & 0.020 \\
\hline \multicolumn{13}{|l|}{ Riboflavin (mg) } \\
\hline $\begin{array}{l}1.1 \text { for females } \\
1.3 \text { for males }\end{array}$ & 0.25 & 0.06 & 0.27 & 0.09 & 0.24 & 0.05 & $<0.001$ & $48 \cdot 14$ & $20 \cdot 82$ & 46.89 & $12 \cdot 69$ & 0.522 \\
\hline \multicolumn{13}{|l|}{$\begin{array}{l}\text { Vitamin } B_{6}(\mathrm{mg}) \\
1.3 \text { for females } 19-50 \text { years }\end{array}$} \\
\hline $\begin{array}{l}1.5 \text { for females } \geq 51 \text { years } \\
1.3 \text { for males } 19-50 \text { years } \\
1.7 \text { for males } \geq 51 \text { years }\end{array}$ & 0.19 & 0.06 & 0.22 & 0.05 & 0.18 & 0.05 & $<0.001$ & $35 \cdot 72$ & 11.37 & 31.59 & $10 \cdot 56$ & 0.003 \\
\hline \multicolumn{13}{|l|}{ Vitamin $B_{12}(\mu \mathrm{g})$} \\
\hline $\begin{array}{l}2.4 \text { for males and females } \\
\text { Niacin (mg) }\end{array}$ & 0.39 & 0.92 & 0.89 & 1.58 & 0.19 & $0 \cdot 19$ & $<0.001$ & $82 \cdot 32$ & $149 \cdot 11$ & 18.96 & 21.11 & $<0.001$ \\
\hline $\begin{array}{l}14 \text { for females } \\
16 \text { for males }\end{array}$ & 3.36 & 0.69 & 3.73 & 0.74 & $3 \cdot 21$ & 0.60 & $<.0001$ & 51.01 & 14.66 & $49 \cdot 42$ & $11 \cdot 37$ & 0.310 \\
\hline \multicolumn{13}{|l|}{ Folate $(\mu \mathrm{g})$} \\
\hline $\begin{array}{l}400 \text { or males and females } \\
\text { Vitamin } C(\mathrm{mg})\end{array}$ & $79 \cdot 24$ & $33 \cdot 18$ & 73.42 & 23.85 & 81.61 & 36.09 & 0.050 & 37.89 & 14.11 & $46 \cdot 68$ & 21.66 & $<0.001$ \\
\hline $\begin{array}{l}45 \text { for males and females } \\
\mathrm{Ca}(\mathrm{mg})\end{array}$ & $\mathrm{Ca}(\mathrm{mg})$ & $5 \cdot 71$ & $16 \cdot 85$ & $5 \cdot 67$ & 11.87 & $5 \cdot 07$ & $<0.001$ & $77 \cdot 73$ & 29.41 & 59.81 & $26 \cdot 44$ & $<0.001$ \\
\hline $\begin{array}{l}1000 \text { for females } 19-50 \text { years } \\
1300 \text { for females } \geq 51 \text { years } \\
1000 \text { for males }\end{array}$ & $136 \cdot 29$ & $41 \cdot 21$ & 133.08 & 39.65 & 137.60 & 41.84 & 0.383 & $27 \cdot 26$ & $10 \cdot 02$ & 30.92 & $10 \cdot 03$ & 0.004 \\
\hline \multicolumn{13}{|l|}{$\mathrm{Fe}(\mathrm{mg}) \dagger$} \\
\hline $\begin{array}{l}22.6 \text { for females } \geq 51 \text { years } \\
27.4 \text { for males }\end{array}$ & $13 \cdot 29$ & 3.77 & $10 \cdot 81$ & $2 \cdot 57$ & $14 \cdot 30$ & $3 \cdot 72$ & $<0.001$ & $67 \cdot 29$ & 31.32 & 85.96 & 41.04 & 0.001 \\
\hline \multicolumn{13}{|l|}{$\mathrm{Zn}(\mathrm{mg}) \ddagger$} \\
\hline $\begin{array}{l}9.8 \text { for females } \\
14.0 \text { for males }\end{array}$ & $3 \cdot 88$ & 0.61 & $3 \cdot 81$ & 0.63 & 3.91 & 0.61 & 0.208 & $65 \cdot 31$ & 18.53 & 78.85 & $19 \cdot 33$ & $<0.001$ \\
\hline
\end{tabular}

\begin{tabular}{|c|c|c|c|c|c|c|c|c|c|c|c|c|}
\hline \multirow{3}{*}{$\begin{array}{l}\text { IIICronutrients (With FAU/VVHU } \\
\text { recommended intake) }\end{array}$} & \multicolumn{6}{|c|}{ kcal)) } & \multicolumn{5}{|c|}{ Mean \% micronutrient adequacy } & \multirow{3}{*}{$P^{\star}$} \\
\hline & \multicolumn{2}{|c|}{ Total $(n 307)$} & \multicolumn{2}{|c|}{$\begin{array}{l}\text { Urban diet } \\
\quad(n 89)\end{array}$} & \multicolumn{2}{|c|}{$\begin{array}{l}\text { Traditional diet } \\
\qquad(n 218)\end{array}$} & \multirow{2}{*}{$P^{\star}$} & \multicolumn{2}{|c|}{$\begin{array}{l}\text { Urban diet } \\
\quad(n 89)\end{array}$} & \multicolumn{2}{|c|}{$\begin{array}{l}\text { Traditional } \\
\text { diet }(n 218)\end{array}$} & \\
\hline & Mean & SD & Mean & SD & Mean & SD & & Mean & SD & Mean & SD & \\
\hline \multicolumn{13}{|l|}{ Vitamin A ( $\mu \mathrm{g} R E)$} \\
\hline $\begin{array}{l}500 \text { for females } \\
600 \text { for males }\end{array}$ & 73.76 & $46 \cdot 11$ & 69.46 & 38.08 & $75 \cdot 51$ & $48 \cdot 99$ & 0.297 & $26 \cdot 56$ & $19 \cdot 13$ & 31.19 & 19.67 & 0.060 \\
\hline \multicolumn{13}{|l|}{ Thiamin (mg) } \\
\hline $\begin{array}{l}1.1 \text { for females } \\
1.2 \text { for males }\end{array}$ & 0.42 & 0.09 & 0.44 & 0.07 & 0.42 & 0.09 & 0.140 & 78.05 & $19 \cdot 21$ & 84.45 & $22 \cdot 74$ & 0.020 \\
\hline \multicolumn{13}{|l|}{ Riboflavin (mg) } \\
\hline $\begin{array}{l}1.1 \text { for females } \\
1.3 \text { for males }\end{array}$ & 0.25 & 0.06 & 0.27 & 0.09 & 0.24 & 0.05 & $<0.001$ & $48 \cdot 14$ & $20 \cdot 82$ & 46.89 & $12 \cdot 69$ & 0.522 \\
\hline \multicolumn{13}{|l|}{ Vitamin $B_{6}(m g)$} \\
\hline $\begin{array}{l}1.5 \text { for females } \geq 51 \text { years } \\
1.3 \text { for males } 19-50 \text { years } \\
1.7 \text { for males } \geq 51 \text { years }\end{array}$ & $0 \cdot 19$ & 0.06 & 0.22 & 0.05 & 0.18 & 0.05 & $<0.001$ & $35 \cdot 72$ & 11.37 & 31.59 & $10 \cdot 56$ & 0.003 \\
\hline \multicolumn{13}{|l|}{ Vitamin $B_{12}(\mu \mathrm{g})$} \\
\hline \multicolumn{13}{|l|}{ Niacin (mg) } \\
\hline $\begin{array}{l}14 \text { for females } \\
16 \text { for males }\end{array}$ & $3 \cdot 36$ & 0.69 & 3.73 & 0.74 & $3 \cdot 21$ & 0.60 & $<.0001$ & $51 \cdot 01$ & 14.66 & 49.42 & 11.37 & 0.310 \\
\hline \multicolumn{13}{|l|}{ Folate $(\mu \mathrm{g})$} \\
\hline \multicolumn{13}{|l|}{ Vitamin C (mg) } \\
\hline \multicolumn{13}{|l|}{$\mathrm{Ca}(\mathrm{mg})$} \\
\hline $\begin{array}{l}1000 \text { for females } 19-50 \text { years } \\
1300 \text { for females } \geq 51 \text { years } \\
1000 \text { for males }\end{array}$ & $136 \cdot 29$ & $41 \cdot 21$ & 133.08 & 39.65 & $137 \cdot 60$ & $41 \cdot 84$ & 0.383 & $27 \cdot 26$ & $10 \cdot 02$ & 30.92 & $10 \cdot 03$ & 0.004 \\
\hline \multicolumn{13}{|l|}{$\mathrm{Fe}(\mathrm{mg}) \dagger$} \\
\hline $\begin{array}{l}22.6 \text { for females } \geq 51 \text { years } \\
27.4 \text { for males }\end{array}$ & $13 \cdot 29$ & 3.77 & $10 \cdot 81$ & $2 \cdot 57$ & $14 \cdot 30$ & $3 \cdot 72$ & $<0.001$ & $67 \cdot 29$ & $31 \cdot 32$ & 85.96 & 41.04 & 0.001 \\
\hline \multicolumn{13}{|l|}{$\mathrm{Zn}(\mathrm{mg}) \ddagger$} \\
\hline $\begin{array}{l}9.8 \text { for females } \\
14.0 \text { for males }\end{array}$ & $3 \cdot 88$ & 0.61 & $3 \cdot 81$ & 0.63 & $3 \cdot 91$ & 0.61 & 0.208 & $65 \cdot 31$ & 18.53 & 78.85 & $19 \cdot 33$ & $<0.001$ \\
\hline
\end{tabular}

$\mathrm{RE}$, retinol equivalent.

${ }^{*}$ Significant difference between groups as determined by Student's $t$ test.

$\dagger 5 \%$ of bioavailability.

‡ Low bioavailability.

Table 5. Macronutrient intakes and total energy according to dietary pattern (Mean values and standard deviations)

\begin{tabular}{|c|c|c|c|c|c|c|c|}
\hline & \multicolumn{6}{|c|}{ Intake according to dietary patterns } & \multirow[b]{3}{*}{$P^{*}$} \\
\hline & \multicolumn{2}{|c|}{ Sample ( $n$ 307) } & \multicolumn{2}{|c|}{ Urban diet $(n 89)$} & \multicolumn{2}{|c|}{ Traditional diet ( $n$ 218) } & \\
\hline & Mean & SD & Mean & SD & Mean & SD & \\
\hline Protein (g/d) & $56 \cdot 1$ & $1056 \cdot 9$ & 52.9 & $1156 \cdot 3$ & 5756.5 & 1056.5 & 056.001 \\
\hline Protein energy (\%) & $1056 \cdot 2$ & $156 \cdot 4$ & $1056 \cdot 3$ & $156 \cdot 1$ & $1056 \cdot 1$ & $156 \cdot 4$ & 056.377 \\
\hline Fat $(\mathrm{g} / \mathrm{d})$ & $4356 \cdot 0$ & 1456.5 & $4556 \cdot 7$ & $1556 \cdot 2$ & $4156 \cdot 9$ & $1456 \cdot 2$ & 056.034 \\
\hline Fat energy (\%) & $1756 \cdot 4$ & 456.9 & $1956 \cdot 6$ & 456.6 & $1656 \cdot 4$ & 456.6 & $<056.001$ \\
\hline Carbohydrate $(\mathrm{g} / \mathrm{d})$ & $41356 \cdot 8$ & $10156 \cdot 1$ & $37056 \cdot 8$ & $8456 \cdot 9$ & $43156 \cdot 7$ & $10256 \cdot 0$ & $<056.001$ \\
\hline Carbohydrate energy (\%) & $7356 \cdot 8$ & $7 \cdot 1$ & $7156 \cdot 6$ & $756 \cdot 0$ & $7456 \cdot 7$ & 656.9 & $<056.001$ \\
\hline Sugar $(g / d)$ & $10656 \cdot 4$ & $11456 \cdot 7$ & $13056 \cdot 4$ & $9856 \cdot 3$ & 9656.6 & $11956 \cdot 6$ & $<056.019$ \\
\hline Sugar energy (\%) & $1756 \cdot 6$ & $1556 \cdot 8$ & $2456 \cdot 1$ & $1756 \cdot 6$ & $1456 \cdot 9$ & $1456 \cdot 3$ & $<056.001$ \\
\hline Fibre $(g / d)$ & 1756.9 & $556 \cdot 8$ & 1456.5 & 356.9 & $1956 \cdot 3$ & 556.9 & $<056.001$ \\
\hline Total energy & & & & & & & $<056.001$ \\
\hline $\mathrm{kJ} / \mathrm{d}$ & $942056 \cdot 7$ & 229456.9 & 869956.0 & 197956.9 & $971456 \cdot 8$ & 235356.5 & \\
\hline $\mathrm{kcal} / \mathrm{d}$ & $225156 \cdot 6$ & 54856.5 & $207956 \cdot 1$ & $47356 \cdot 2$ & $232156 \cdot 9$ & 56256.5 & \\
\hline
\end{tabular}

* Significant difference between groups as determined by Student's $t$ test. 
Table 6. Micronutrient deficiency and cardiometabolic risk factors according to physical activity and dietary pattern (Means values and standard deviations, numbers of subjects and odds ratios)

\begin{tabular}{|c|c|c|c|c|c|c|c|c|c|c|c|}
\hline & \multicolumn{6}{|c|}{$\begin{array}{l}\text { Daily physical activity by intensity level according to } \\
\qquad \operatorname{MET}(\mathrm{h} / \mathrm{d})\end{array}$} & \multicolumn{5}{|c|}{ Dietary patterns: odds of risk in 'traditional' $v$. 'urban' pattern } \\
\hline & \multicolumn{2}{|c|}{$\begin{array}{l}\text { Active hours } \\
\text { (>3 MET) }\end{array}$} & \multirow[b]{2}{*}{$P^{\star}$} & \multicolumn{2}{|c|}{$\begin{array}{c}\text { Sedentary } \\
\text { hours }(\leq 3 \\
\text { MET) }\end{array}$} & \multirow[b]{2}{*}{$P^{\star}$} & \multirow{2}{*}{$\begin{array}{l}\text { ‘Urban’ diet } \\
\quad(n 89)\end{array}$} & \multirow{2}{*}{$\begin{array}{l}\text { 'Traditional' diet } \\
\text { (n 218) }\end{array}$} & \multirow[b]{2}{*}{ OR } & \multirow[b]{2}{*}{$95 \% \mathrm{Cl}$} & \multirow[b]{2}{*}{$P^{\star}$} \\
\hline & Mean & SD & & Mean & SD & & & & & & \\
\hline \multicolumn{12}{|l|}{ Micronutrient deficiency markers } \\
\hline \multicolumn{12}{|l|}{$\mathrm{Hb}$ status } \\
\hline Non-anaemic (n 228) & $4 \cdot 2$ & 2.4 & & $11 \cdot 3$ & $3 \cdot 3$ & & 73 & 155 & 1.00 & & \\
\hline Anaemic $(n 79)$ & $4 \cdot 7$ & $2 \cdot 2$ & 0.157 & $11 \cdot 8$ & 2.7 & 0.209 & 16 & 63 & 1.85 & $1 \cdot 0,3 \cdot 4$ & 0.049 \\
\hline \multicolumn{12}{|l|}{ Fe status } \\
\hline Normal Fe (n 260) & $4 \cdot 3$ & 2.5 & & $11 \cdot 3$ & $3 \cdot 2$ & & 83 & 177 & 1.00 & & \\
\hline Deficient (n 47) & 4.5 & 1.8 & 0.736 & $12 \cdot 2$ & 2.5 & 0.082 & 6 & 41 & $3 \cdot 27$ & $1 \cdot 3,8 \cdot 0$ & 0.009 \\
\hline \multicolumn{12}{|l|}{ Vitamin A status } \\
\hline Normal (n 267) & $4 \cdot 3$ & $2 \cdot 4$ & & 11.5 & $3 \cdot 1$ & & 84 & 183 & 1.00 & & \\
\hline Deficient ( $n$ 40) & 4.9 & 1.9 & 0.100 & $10 \cdot 9$ & $3 \cdot 0$ & 0.287 & 5 & 35 & $3 \cdot 21$ & $1 \cdot 2,8 \cdot 5$ & 0.019 \\
\hline \multicolumn{12}{|l|}{ Cardiometabolic markers } \\
\hline \multicolumn{12}{|l|}{ BMI } \\
\hline 18.5-24.9 (n 203) & $4 \cdot 6^{\mathrm{a}}$ & 2.5 & & $11 \cdot 1^{\mathrm{a}}$ & $3 \cdot 1$ & & 55 & 148 & 1.00 & & \\
\hline$<18.5(n 30)$ & $4 \cdot 5^{\mathrm{a}, \mathrm{b}}$ & 2.8 & & $11 \cdot 1^{\mathrm{a}, \mathrm{b}}$ & 3.4 & & 8 & 22 & 1.02 & $0.4,2.4$ & 0.961 \\
\hline$\geq 25(n 74)$ & $3 \cdot 6^{\mathrm{C}}$ & 1.6 & 0.008 & $12 \cdot 5^{\mathrm{c}}$ & $2 \cdot 8$ & 0.003 & 26 & 48 & 0.68 & $0.4,1.2$ & 0.194 \\
\hline \multicolumn{12}{|l|}{ Waist circumference } \\
\hline Normal (n 235) & $4 \cdot 6$ & 2.5 & & $11 \cdot 2$ & $3 \cdot 1$ & & 65 & 170 & 1.00 & & \\
\hline Abdominal obesity ( $n$ 72) & $3 \cdot 7$ & $1 \cdot 7$ & 0.010 & $12 \cdot 4$ & $3 \cdot 0$ & 0.004 & 24 & 48 & $0 \cdot 76$ & $0.4,1 \cdot 3$ & 0.354 \\
\hline \multicolumn{12}{|l|}{ Percentage body fat } \\
\hline Normal (n 235) & $4 \cdot 6$ & 2.5 & & $11 \cdot 1$ & $3 \cdot 2$ & & 67 & 167 & 1.00 & & \\
\hline High (n 72) & 3.6 & 1.6 & 0.001 & $12 \cdot 6$ & $2 \cdot 7$ & $<0.001$ & 22 & 51 & 0.91 & $0.5,1.6$ & 0.753 \\
\hline \multicolumn{12}{|l|}{ Glycaemia } \\
\hline Normal (n 201) & $4 \cdot 1$ & $2 \cdot 2$ & & 11.5 & 2.9 & & 58 & 143 & 1.00 & & \\
\hline High (n 106) & $4 \cdot 7$ & $2 \cdot 6$ & 0.043 & $11 \cdot 3$ & 3.4 & 0.553 & 31 & 75 & 0.94 & $0 \cdot 6,1 \cdot 6$ & 0.943 \\
\hline Blood pressure & & & & & & & & & & & \\
\hline Normal blood pressure (n 196) & $4 \cdot 7$ & $2 \cdot 6$ & & 11.4 & $3 \cdot 2$ & & 63 & 133 & 1.00 & & \\
\hline High blood pressure $(n 111)$ & $3 \cdot 8$ & 1.9 & 0.002 & $11 \cdot 6$ & $3 \cdot 0$ & 0.590 & 26 & 85 & 1.54 & $0.9,2.4$ & 0.107 \\
\hline HDL-cholesterol & & & & & & & & & & & \\
\hline Normal (n 215) & 4.4 & 2.5 & & $11 \cdot 2$ & $3 \cdot 2$ & & 67 & 148 & 1.00 & & \\
\hline Low (n 92) & $4 \cdot 3$ & $2 \cdot 1$ & 0.758 & 11.9 & 2.9 & 0.054 & 22 & 70 & 1.44 & $0.8,2.5$ & 0.201 \\
\hline Triacylglycerolaemia & & & & & & & & & & & \\
\hline Normal (n 301) & $4 \cdot 4$ & $2 \cdot 3$ & & 11.4 & $3 \cdot 1$ & & 88 & 213 & 1.00 & & \\
\hline $\begin{array}{l}\text { Hypertriacylglycerolaemia } \\
(n 6)\end{array}$ & $2 \cdot 3$ & 0.3 & 0.029 & $12 \cdot 7$ & $3 \cdot 0$ & 0.323 & 1 & 5 & 2.06 & $0.2,17.9$ & 0.511 \\
\hline Clustering of MetS factors & & & & & & & & & & & \\
\hline Zero factors ( $n$ 75) & $4 \cdot 9^{\mathrm{a}}$ & $2 \cdot 6$ & & $10 \cdot 7^{\mathrm{a}}$ & 2.9 & & 27 & 48 & 1.00 & & \\
\hline $\begin{array}{l}\text { One factor or two factors } \\
(n 200)\end{array}$ & $4 \cdot 3^{a, b}$ & $2 \cdot 3$ & & $11 \cdot 6^{\mathrm{a}, \mathrm{b}}$ & $3 \cdot 2$ & & 54 & 146 & 1.52 & $0 \cdot 8,2 \cdot 7$ & 0.146 \\
\hline MetS ( $n$ 32) & $3 \cdot 7^{\mathrm{b}, \mathrm{c}}$ & $1 \cdot 8$ & 0.043 & $12 \cdot 1^{\mathrm{b}, \mathrm{c}}$ & $2 \cdot 7$ & 0.039 & 8 & 24 & 1.68 & $0 \cdot 7,4 \cdot 3$ & 0.269 \\
\hline LDL-cholesterol & & & & & & & & & & & \\
\hline Normal (n 276) & 4.5 & $2 \cdot 4$ & & 11.4 & $3 \cdot 2$ & & 81 & 276 & 1.00 & & \\
\hline High (n 31) & 3.5 & $1 \cdot 8$ & 0.028 & $12 \cdot 2$ & $2 \cdot 8$ & $0 \cdot 180$ & 8 & 23 & $1 \cdot 19$ & $0.5,2 \cdot 7$ & 0.680 \\
\hline Insulin resistance & & & & & & & & & & & \\
\hline No $(n 229)$ & 4.5 & 2.5 & & $11 \cdot 2$ & $3 \cdot 3$ & & 64 & 165 & 1.00 & & \\
\hline Yes (n 78) & $3 \cdot 8$ & $1 \cdot 8$ & 0.019 & $12 \cdot 0$ & 2.7 & 0.063 & 25 & 53 & 0.82 & $0.5,1.4$ & 0.491 \\
\hline
\end{tabular}

MET, metabolic equivalent of tasks; MetS, metabolic syndrome.

* Significant difference between groups as determined by Student's $t$ test, $\chi^{2}$ test or one-way ANOVA with the Bonferroni post hoc test for multiple comparisons.

a,b,c Values within a column with unlike superscript letters were significantly different (one-way ANOVA).

group, with subjects exhibiting overweight/obesity plus at least one micronutrient deficiency ( $8.46 \%)$; and phenotype 5 , the second 'double burden' group with subjects having CMRF other than overweight/obesity associated with at least one micronutrient deficiency or underweight $(17.58$ $\%)$. Using phenotype 1 ('normal' subjects) as the reference group, the multinomial logistic regression showed (Table 8) that subjects with more sedentary time (OR 1.17; $95 \% \mathrm{CI}$ $1.02,1.49 ; P=0.038)$ were more likely to be found in phenotype 4 (co-occurrence of overweight/obesity plus micronutrient deficiencies), while men and middle-income subjects were less likely to have this phenotype. Subjects with a 'traditional' diet pattern (OR 3.04; $95 \%$ CI 1.01, 9.22; $P=0.050)$ were more likely to present the 'phenotype 5' (co-occurrence of other CMRF associated with micronutrient deficiencies or underweight), while men and middle-income subjects were less likely to have this phenotype. Of note, middle-income subjects were at lower odds 


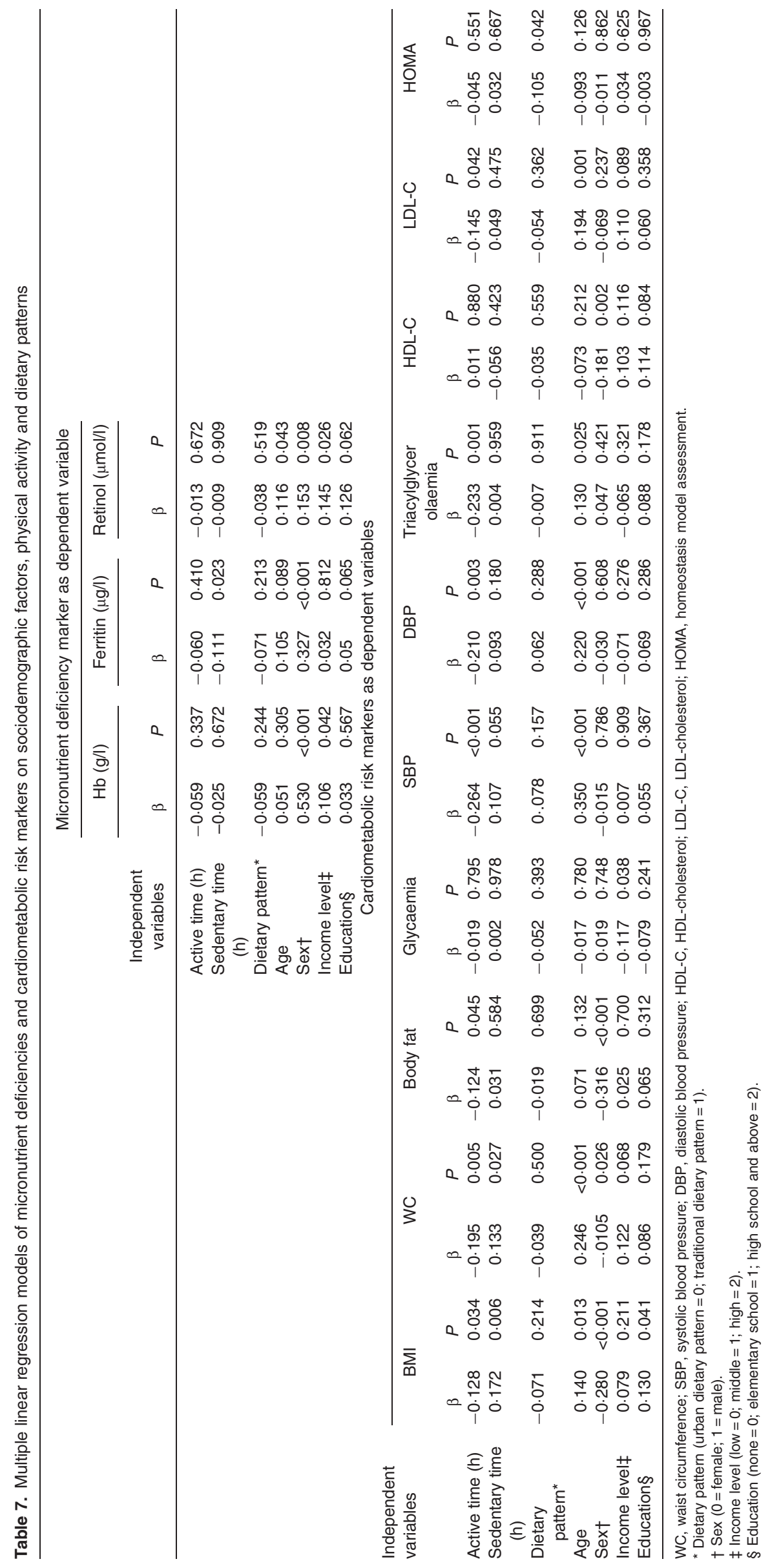




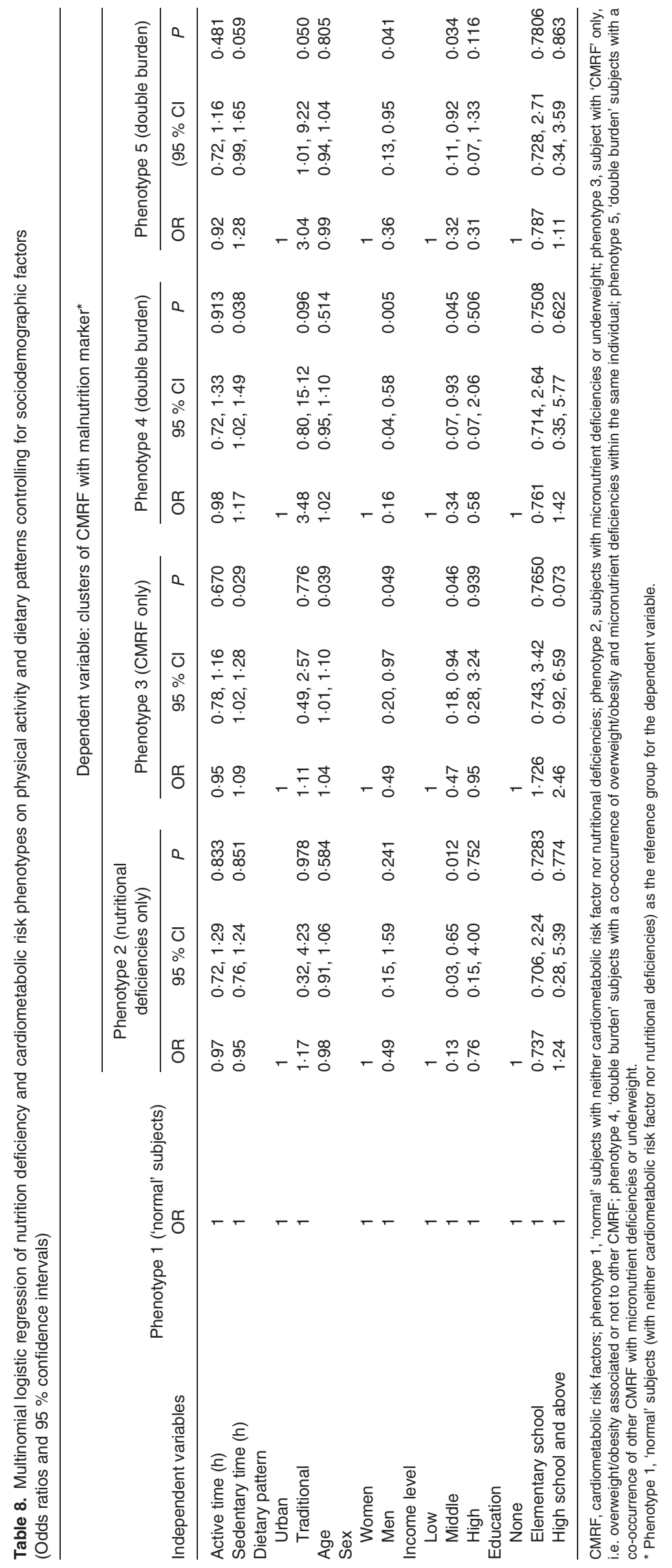


of all nutritional burden phenotypes, whereas education level showed no association with these phenotypes.

\section{Discussion}

In this cross-sectional study in an adult population of Ouagadougou, we identified two dietary patterns using cluster analysis. This approach, by addressing nutrient interactions and considering diet as a whole rather than focusing on specific foods or nutrients, is more and more valued in epidemiological studies ${ }^{(47)}$. The 'urban' dietary pattern was indeed more city-like because of higher consumption of soft drinks, non-traditional vegetables and imported cereals such as rice and wheat products, which are typically eaten in urban areas. The 'traditional' dietary pattern was predominantly characterised by higher intake of traditional green leafy vegetables and local cereals (millet and maize) typical of rural areas.

We did not observe in the present study population an advanced stage of dietary transition with Westernised ${ }^{(4,48)}$ food habits characterised by high intake of processed foods, animal products and other foods high in fat, and sweets as substitutes for traditional foods. However, we documented in $29 \%$ of the subjects an 'urban' dietary pattern with a more diversified diet according to the number of food groups consumed, and with imported foods being added to the 'traditional' diet base. Similar findings were reported in Benin ${ }^{(49)}$, a neighbouring country, where the 'transitional' diet consisted of a 'traditional' diet plus added Western foods which do not displace traditional foods, at least not as yet. While the 'urban' diet in Ouagadougou was higher in fat and sugar that the traditional diet, fat intake was low in both dietary patterns as it did not reach $20 \%$ of total energy intake. In contrast, sugar intake was high, representing well above $10 \%$ of total energy as recommended by $\mathrm{WHO}^{(29)}$. While the 'traditional' diet was higher in fibre than the 'urban' diet, it was still lower than the recommended $25 \mathrm{~g} / \mathrm{d}$.

Higher-income, more-educated and male subjects were significantly aggregated in the 'urban' diet cluster, while there were proportionally more lower-income, non-educated and female subjects in the 'traditional' diet cluster. These data are in agreement with several previous studies showing an association between dietary patterns and socio-economic characteristics ${ }^{(49-51)}$. Studies on dietary patterns in different populations such as Brazil ${ }^{(52)}$, Korea ${ }^{(51)}$ and Greece ${ }^{(53)}$ usually documented the presence of 'traditional' dietary patterns (based on staples and other traditional foods), as well as modified dietary patterns characterised by highly processed foods, refined sugar and grains, and abundance of energy-dense and micronutrient-poor foods. In the present study, both dietary patterns had a low micronutrient density, with a micronutrient adequacy below $60 \%$ of the recommended intake for six out of eleven micronutrients. The significant aggregation of anaemic, Fe-deficient and vitamin A-deficient subjects in the 'traditional' diet cluster, in spite of the higher percentage adequacy for $\mathrm{Fe}$ and vitamin $\mathrm{A}$ in this diet, may reflect the lower bioavailability of $\mathrm{Fe}$ and lower vitamin $\mathrm{A}$ activity of plant sources of carotenoids in the cereal- and green leafy-based 'traditional' diet, compared with the 'urban' diet that includes more meat.
The present results further demonstrate that the 'urban' dietary pattern was significantly and independently associated with insulin resistance. While dietary fat intake, particularly saturated fat, has been shown to be associated with insulin resistance ${ }^{(54-56)}$, a recent and extensive review on the relationship between carbohydrate intake and insulin resistance ${ }^{(57)}$ could not demonstrate a clear and consistent association. This is in line with our findings, as the 'urban' diet exhibited significantly higher intake of fat and fat contribution to energy, whereas the 'traditional' diet had higher intake of carbohydrate. The shift toward 'urban' or even 'Western' dietary patterns will probably continue and the present findings on the association of the 'urban' diet with insulin resistance is of particular concern, as it is in line with the International Diabetes Federation ${ }^{(58)}$ projections on diabetes increase in developing countries until 2030. The unexpected association between high glycaemia and low income is another matter for concern, as this metabolic risk factor seems to no longer be a problem of affluent individuals only. A closer look shows that $63.2 \%$ ( $n$ 68) of high glycaemia subjects ( $55 \%$ of them belong to the low-income group) were not insulin resistant, i.e. these subjects exhibited lower levels of insulin while having high glycaemia; otherwise they would have been in the insulin-resistant group. Among these non-insulin-resistant and high glycaemia subjects, $15 \%$ were underweight and only $20.6 \%$ were overweight/obese. Such results legitimate the questioning raised in previous reports ${ }^{(59,60)}$ about the insulin-requiring diabetes or malnutrition-related diabetes in African populations and stress the need for more African studies to investigate this specific issue further.

In contrast ${ }^{(61-63)}$ or in agreement ${ }^{(51,64-66)}$ with other studies, we observed no statistical difference in the OR of overweight/ obesity or abdominal obesity according to dietary clusters. Energy intake was significantly higher in the 'traditional' cluster, but so was physical activity ('active' time in the present study), very much like several other studies showing that rural individuals with traditional diets have higher energy intake and also higher energy expenditure than their urban counterparts.

As expected, subjects with overweight/obesity, abdominal obesity, higher body fat, high glycaemia, high blood pressure, high triacylglycerolaemia, high LDL-C, insulin resistance and those with the MetS had significantly less active time, and also consistently showed higher sedentary time (except for high glycaemia, high blood pressure, high triacylglycerolaemia, LDL-C and insulin resistance). Daily physical activity has consistently been shown to reduce abdominal or overall obesity, and improve glucose homeostasis, insulin sensitivity, blood pressure and circulating lipoprotein profile, whether in developing $^{(6,67-69)}$ or developed ${ }^{(70,71)}$ country populations. The central role of physical activity in CVD prevention ${ }^{(72,73)}$ is widely recognised. Several African studies ${ }^{(68,69,74)}$ have reported that rural populations have higher physical activity than their urban counterparts, with high-income groups in urban areas being less active than low-income ones. Consistent with these findings, the present results portrayed significantly higher sedentary time in women, high-income, as well as in more-educated subjects. Deterrents to physical activity such 
as the low status and lack of promotion of physical activity, as well as the absence of sidewalks and insecurity of walking, may be at play in urban Africa and need to be addressed in order to halt the progression of NCD.

We also reported an independent and significant association between sedentary time and Fe deficiency. Keeping in mind that sedentary time is significantly higher in overweight/ obese subjects, this finding supports a possible increased risk of Fe deficiency in overweight/obese individuals ${ }^{(75-77)}$, a condition that could therefore promote the double burden of malnutrition.

We have used in the present paper more sensitive cut-offs for high blood pressure, glycaemia and $\mathrm{WC}^{(30)}$ than in a previous paper $^{(11)}$ and we report a $26 \%$ double burden of malnutrition, compared with $23.5 \%{ }^{(11)}$. Generic WC cut-offs used may not be appropriate for Africans, as recently reported $^{(78)}$. Sedentary time, low income status and the 'traditional' dietary pattern (borderline) appeared to be associated with the co-occurrence of overweight/obesity plus micronutrient deficiencies (phenotype 4). Sedentary time (borderline), low income status, female sex and 'traditional' dietary pattern were also significantly associated with the co-occurrence of other CMRF plus underweight or micronutrient deficiencies (phenotype 5). Given the low micronutrient density of the 'traditional' diet, it is not surprising that this dietary pattern was associated with the two phenotypes of double burden, because these imply micronutrient deficiencies in addition to CMRF. Middle-income subjects appeared less affected by micronutrient deficiencies, CMRF and their co-occurrence. One should note that middle-income subjects were aggregated without statistical difference in both 'urban' and 'traditional' diet clusters, with active time significantly lower than that of the low-income group but also higher than that of the highincome group. These findings suggest that the middle-income subjects may be less exposed to two kinds of risk: the deficiencies experienced by the poor and the unhealthy lifestyles of more affluent. The variable most consistently associated with overweight/obesity in the present study was sedentary time, explaining the association of a sedentary lifestyle with phenotype 4 of double burden and a borderline association with phenotype 5 of double burden. One should keep in mind that poverty and female sex were strongly associated with the 'traditional' diet pattern. 'This dietary pattern was less diversified, a common feature of food insecurity, which is known to be more prevalent among the poor and particularly among women $^{(16,79,80)}$. In fact, almost $52 \%$ of Ouagadougou ${ }^{(81)}$ households reportedly experience chronic food insecurity. These findings fit with the hypothesis that in food-insecure households, cheap and energy-dense foods may contribute to overweight in adults, while not sustaining a healthy nutritional status due in part to inadequate micronutrient density ${ }^{(17,82,83)}$. In such context, having enough food to ward off hunger is the main concern of individuals.

Several limitations can be identified in the present study. The cross-sectional design does not allow any inference to be drawn with regard to causal relationships. Furthermore, the study is only representative of one district in Ouagadougou and the results cannot be extrapolated to the whole urban population of Burkina Faso without extreme caution. The cluster analysis used in the present study to identify the different food patterns is open to several criticisms: It involves subjective decisions as regards food grouping and cluster labelling. Variations across studies in cluster numbers and characteristics preclude comparisons. Nonetheless, dietary patterns were based on rigorous dietary assessment. We conducted two $24 \mathrm{~h}$ dietary recalls using a validated multiple-pass method to reduce memory bias. Additionally, C-SIDE software was used for the reduction of the intra-individual intake variation. Unfortunately, we could not compute the SFA and PUFA and cholesterol intakes that would have been helpful for the assessment of diet healthfulness. Other limitations are that measuring physical activity with $24 \mathrm{~h}$ recalls is a method that has not been validated as yet. Finally, the duration of the data collection period (from January to July) is another limitation, as seasonal variations cannot be captured while they may confound some findings.

Despite these limitations, the present study provides useful data on the ongoing nutrition transition in Ouagadougou and reports for the first time the coexistence of malnutrition and nutrition-related NCD risk factors in the same individual urban adults. Indeed, our data clearly show that a nutrition transition is underway in this adult population of Ouagadougou, affecting both food and physical activity patterns. Interestingly, the nutrition transition, rather than promoting an isolated rise in CMRF, fosters the double burden of malnutrition because deficiency conditions persist. Concerted efforts at national and international levels are compelling in low-income countries in order to halt the NCD epidemic while also addressing nutritional deficiencies.

\section{Acknowledgements}

The present study was funded by the Canadian International Development Agency.

We gratefully acknowledge the technical and field support provided by the Institut de Recherche en Sciences de la Santé (IRSS; Burkina Faso Health Sciences Research Institute) and Institut supérieur en sciences de la population (ISSP; Burkina Faso Higher Institute of Population Sciences). We would like to thank Professor Somé Issa of Université de Ouagadougou and Professor Jean-Louis Guéant of Nancy-University for laboratory analyses. We also thank the population of the Population Observatory of Ouagadougou' and all the field workers involved in the study.

A. N. Z. developed the study protocol as his PhD project, collected and analysed the data, and drafted the manuscript. G. R. was involved in the study design and paper revision. H. F. D. designed the study and supervised data analysis and paper revision.

The authors declare no competing interests.

\section{References}

1. Despres JP, Cartier A, Cote M, et al. (2008) The concept of cardiometabolic risk: bridging the fields of diabetology and cardiology. Ann Med 40, 514-523. 
2. Abegunde DO, Mathers CD, Adam T, et al. (2007) The burden and costs of chronic diseases in low-income and middle-income countries. Lancet 370, 1929-1938.

3. Misra A \& Khurana L (2008) Obesity and the metabolic syndrome in developing countries. J Clin Endocrinol Metab 93, S9-S30.

4. Popkin BM (2006) Global nutrition dynamics: the world is shifting rapidly toward a diet linked with noncommunicable diseases. $A m \mathrm{~J}$ Clin Nutr 84, 289-298.

5. World Health Organization (2003) Diet, Nutrition and the Prevention of Chronic Diseases. Joint WHO/FAO Expert Consultation. WHO Technical Report Series no. 916. Geneva: WHO.

6. Forrest KY, Bunker CH, Kriska AM, et al. (2001) Physical activity and cardiovascular risk factors in a developing population. Med Sci Sports Exerc 33, 1598-1604.

7. Kruger HS, Venter CS, Vorster HH, et al. (2002) Physical inactivity is the major determinant of obesity in black women in the North West Province, South Africa: the THUSA study. Transition and Health During Urbanisation of South Africa. Nutrition 18, 422-427.

8. Brundtland GH (2002) From the World Health Organization. Reducing risks to health, promoting healthy life. JAMA 288, 1974.

9. Black RE, Allen LH, Bhutta ZA, et al. (2008) Maternal and child undernutrition: global and regional exposures and health consequences. Lancet 371, 243-260.

10. West KP Jr (2002) Extent of vitamin A deficiency among preschool children and women of reproductive age. J Nutr 132, 2857S-2866S.

11. Zeba AN, Delisle HF, Renier G, et al. (2012) The double burden of malnutrition and cardiometabolic risk widens the gender and socioeconomic health gap: a study among adults in Burkina Faso (West Africa). Public Health Nutr 15, 2210-2219.

12. Tupe R, Chiplonkar SA \& Kapadia-Kundu N (2009) Influence of dietary and socio-demographic factors on the iron status of married adolescent girls from Indian urban slums. Int J Food Sci Nutr 60, $51-59$.

13. Alaofè H, Zee J \& Turgeon O'Brien H (2007) Dietary iron and iron deficiency anemia among adolescent girls from Benin (article in French). Rev Epidemiol Sante Publique 55, 187-196.

14. Thankachan P, Muthayya S, Walczyk T, et al. (2007) An analysis of the etiology of anemia and iron deficiency in young women of low socioeconomic status in Bangalore, India. Food Nutr Bull 28, 328-336.

15. Allen LH (1994) Nutritional influences on linear growth: a general review. Eur J Clin Nutr 48, Suppl. 1, S75-S89.

16. Delisle HF (2008) Poverty: the double burden of malnutrition in mothers and the intergenerational impact. Ann N Y Acad Sci 1136, 172-184.

17. Tanumihardjo SA, Anderson C, Kaufer-Horwitz M, et al. (2007) Poverty, obesity, and malnutrition: an international perspective recognizing the paradox. J Am Diet Assoc 107, 1966-1972.

18. United Nations General Assembly (2011) Political Declaration of the High-level Meeting of the General Assembly on the Prevention and Control of Non-communicable Diseases (A/66/L.1). New York: United Nations General Assembly.

19. Block G, Jensen CD, Norkus EP, et al. (2008) Vitamin C in plasma is inversely related to blood pressure and change in blood pressure during the previous year in young Black and White women. Nutr J 7,35 .

20. Ford ES, Will JC, Bowman BA, et al. (1999) Diabetes mellitus and serum carotenoids: findings from the Third National Health and Nutrition Examination Survey. Am J Epidemiol 149, 168-176.

21. Deleuze Ntandou Bouzitou G, Fayomi B \& Delisle H (2005) Child malnutrition and maternal overweight in same households in poor urban areas of Benin (article in French). Sante 15, 263-270.

22. Raphaël D, Delisle HF \& Vilgrain C (2005) Households with undernourished children and overweight mothers: is this a concern for Haiti? Ecol Food Nutr 44, 147-165.

23. Delisle H, Agueh V \& Fayomi B (2011) Partnership research on nutrition transition and chronic diseases in West Africa - trends, outcomes and impacts. BMC Int Health Hum Rights 11, Suppl. 2, S10.
24. City Development Strategy (2007) Etude Diagnostique de L'agglomération de Onagadongon (Diagnostic Study of Onagadongon Agglomeration). Ouagadougou: CDS.

25. Niakara A, Fournet F, Gary J, et al. (2007) Hypertension, urbanization, social and spatial disparities: a cross-sectional populationbased survey in a West African urban environment (Ouagadougou, Burkina Faso). Trans R Soc Trop Med Hyg 101, 1136-1142.

26. Direction de la Nutrition (2006) Analyse Complémentaire de la Situation Nutritionnelle au Burkina Faso: Rapport Final (Complementary Analysis of the Nutritional Situation in Burkina Faso: Final Report). Ouagadougou: Ministère de la Santé du Burkina Faso.

27. Becquey E \& Martin-Prevel Y (2010) Micronutrient adequacy of women's diet in urban Burkina Faso is low. J Nutr 140, 2079S2085S.

28. Lohman T, Roche A \& Martorell R (1988) Anthropometric Standardization Reference Manual. Champaign, IL: Human Kinetics Books.

29. World Health Organization (2000) Obesity: Preventing and Managing the Global Epidemic. Report of a WHO Consultation on Obesity. Technical Report Series no. 894.Geneva: WHO.

30. Alberti KG, Eckel RH, Grundy SM, et al. (2009) Harmonizing the metabolic syndrome: a joint interim statement of the International Diabetes Federation Task Force on Epidemiology and Prevention; National Heart, Lung, and Blood Institute; American Heart Association; World Heart Federation; International Atherosclerosis Society; and International Association for the Study of Obesity. Circulation 120, 1640-1645.

31. Sun SS, Chumlea WC, Heymsfield SB, et al. (2003) Development of bioelectrical impedance analysis prediction equations for body composition with the use of a multicomponent model for use in epidemiologic surveys. Am J Clin Nutr 77, 331-340.

32. Jackson AS, Stanforth PR, Gagnon J, et al. (2002) The effect of sex, age and race on estimating percentage body fat from body mass index: The Heritage Family Study. Int J Obes Relat Metab Disord 26, 789-796.

33. World Health Organization (1999) The Metabolic Syndrome. Definition, Diagnosis and Classification of Diabetes Mellitus and its Complications. Part 1: Diagnosis and Classification of Diabetes Mellitus. Geneva: WHO.

34. Millan J, Pinto X, Munoz A, et al. (2009) Lipoprotein ratios: physiological significance and clinical usefulness in cardiovascular prevention. Vasc Health Risk. Manag 5, 757-765.

35. Matthews DR, Hosker JP, Rudenski AS, et al. (1985) Homeostasis model assessment: insulin resistance and beta-cell function from fasting plasma glucose and insulin concentrations in man. Diabetologia 28, 412-419.

36. World Health Organization (2009) Global Prevalence of Vitamin A Deficiency in Populations at Risk 1995-2005. WHO Global Database on Vitamin A Deficiency. Geneva: WHO.

37. World Health Organization (2004) Assessing the Iron Status of Populations: Including Literature Reviews. Report of a Joint WHO/CDC and Prevention Technical Consultation on the Assessment of Iron Status at the Population Level, 6-8 April 2004. Geneva: WHO.

38. Conway JM, Ingwersen LA \& Moshfegh AJ (2004) Accuracy of dietary recall using the USDA five-step multiple-pass method in men: an observational validation study. J Am Diet Assoc 104, 595-603.

39. Nordeide MB (1998) Cartographer Table de Composition d'Aliments du Mali (The Composition of Mailain Foods). Bamako, Mali: Projet de Recherche SSE; Oslo: Nordic School of Nutrition, University of Oslo.

40. Nusser SM, Carriquiry AL, Dodd KW, et al. (1996) A semiparametric transformation approach to estimating usual daily intake distributions. I Am Stat Assoc 91, 1440-1449.

41. Moeller SM, Reedy J, Millen AE, et al. (2007) Dietary patterns: challenges and opportunities in dietary patterns research: an experimental biology workshop, April 1, 2006. J Am Diet Assoc 107, 12331239. 
42. Newby PK \& Tucker KL (2004) Empirically derived eating patterns using factor or cluster analysis: a review. Nutr Rev 62, 177-203.

43. World Health Organization \& Food and Agriculture Organization (2001) Human Vitamin and Mineral Requirements: Report of a Joint FAO/WHO Expert Consultation. Rome: FAO.

44. Gortmaker SL, Cheung LW, Peterson KE, et al. (1999) Impact of a school-based interdisciplinary intervention on diet and physical activity among urban primary school children: eat well and keep moving. Arch Pediatr Adolesc Med 153, 975-983.

45. Ainsworth BE, Haskell WL, Whitt MC, et al. (2000) Compendium of physical activities: an update of activity codes and MET intensities. Med Sci Sports Exerc 32, S498-S504.

46. World Health Organization (2003) Population nutrient intake goals for preventing diet-related chronic diseases. In Diet, Nutrition and the Prevention of Chronic Diseases. Joint WHO/FAO Expert Consultation. WHO Technical Report Series no. 916, pp. 54-133. Geneva: World Health Organization.

47. Hu FB (2002) Dietary pattern analysis: a new direction in nutritional epidemiology. Curr Opin Lipidol 13, 3-9.

48. Popkin BM (2002) An overview on the nutrition transition and its health implications: the Bellagio meeting. Public Health Nutr 5, 93-103.

49. Sodjinou R, Agueh V, Fayomi B, et al. (2009) Dietary patterns of urban adults in Benin: relationship with overall diet quality and socio-demographic characteristics. Eur J Clin Nutr 63, 222-228.

50. Sanchez-Villegas A, Delgado-Rodriguez M, Martinez-Gonzalez MA, et al. (2003) Gender, age, socio-demographic and lifestyle factors associated with major dietary patterns in the Spanish Project SUN (Seguimiento Universidad de Navarra). Eur J Clin Nutr 57, 285-292.

51. Song Y, Joung H, Engelhardt K, et al. (2005) Traditional v. modified dietary patterns and their influence on adolescents' nutritional profile. Br J Nutr 93, 943-949.

52. Sichieri R (2002) Dietary patterns and their associations with obesity in the Brazilian city of Rio de Janeiro. Obes Res 10, 42-48.

53. Costacou T, Bamia C, Ferrari P, et al. (2003) Tracing the Mediterranean diet through principal components and cluster analyses in the Greek population. Eur J Clin Nutr 57, 1378-1385.

54. Marshall JA, Hoag S, Shetterly S, et al. (1994) Dietary fat predicts conversion from impaired glucose tolerance to NIDDM. The San Luis Valley Diabetes Study. Diabetes Care 17, 50-56.

55. Mayer-Davis EJ, Monaco JH, Hoen HM, et al. (1997) Dietary fat and insulin sensitivity in a triethnic population: the role of obesity. The Insulin Resistance Atherosclerosis Study (IRAS). Am J Clin Nutr 65, 79-87.

56. Hung T, Sievenpiper JL, Marchie A, et al. (2003) Fat versus carbohydrate in insulin resistance, obesity, diabetes and cardiovascular disease. Curr Opin Clin Nutr Metab Care 6, 165-176.

57. McClenaghan NH (2005) Determining the relationship between dietary carbohydrate intake and insulin resistance. Nutr Res Rev 18, 222-240.

58. International Diabetes Federation (2009) Diabetes Atlas, 4th ed. Brussels: International Diabetes Federation.

59. Habtu E, Gill G \& Tesfaye S (1999) Characteristics of insulin requiring diabetes in rural northern Ethiopia - a possible link with malnutrition? Ethiop Med J 37, 263-267.

60. Alemu S, Dessie A, Seid E, et al. (2009) Insulin-requiring diabetes in rural Ethiopia: should we reopen the case for malnutrition-related diabetes? Diabetologia 52, 1842-1845.

61. Flores M, Macias N, Rivera M, et al. (2010) Dietary patterns in Mexican adults are associated with risk of being overweight or obese. J Nutr 140, 1869-1873.

62. Cunha DB, de Almeida RM, Sichieri R, et al. (2010) Association of dietary patterns with BMI and waist circumference in a low-income neighbourhood in Brazil. Br J Nutr 104, 908-913.

63. Denova-Gutierrez E, Castanon S, Talavera JO, et al. (2010) Dietary patterns are associated with metabolic syndrome in an urban Mexican population. J Nutr 140, 1855-1863.
64. Delisle HF, Vioque J \& Gil A. (2009) Dietary patterns and quality in West-African immigrants in Madrid. Nutr J 8, 3.

65. Newby PK, Muller D \& Tucker KL (2004) Associations of empirically derived eating patterns with plasma lipid biomarkers: a comparison of factor and cluster analysis methods. Am J Clin Nutr 80, 759-767.

66. Sichieri R, Moura AS, Genelhu V, et al. (2007) An 18-mo randomized trial of a low-glycemic-index diet and weight change in Brazilian women. Am J Clin Nutr 86, 707-713.

67. Muhihi A, Njelekela M, Mpembeni R, et al. (2012) Physical activity and cardiovascular disease risk factors among young and middle-aged men in urban Mwanza, Tanzania. Pan Afr Med J 11, 11.

68. Mbalilaki JA, Hellenius ML, Masesa Z, et al. (2007) Physical activity and blood lipids in rural and urban Tanzanians. Nutr Metab Cardiovasc Dis 17, 344-348.

69. Sobngwi E, Mbanya JC, Unwin NC, et al. (2002) Physical activity and its relationship with obesity, hypertension and diabetes in urban and rural Cameroon. Int J Obes Relat Metab Disord 26, 1009-1016.

70. Krishnan S, Rosenberg L \& Palmer JR (2009) Physical activity and television watching in relation to risk of type 2 diabetes: the Black Women's Health Study. Am J Epidemiol 169, 428-434.

71. Woolf K, Reese CE, Mason MP, et al. (2008) Physical activity is associated with risk factors for chronic disease across adult women's life cycle. J Am Diet Assoc 108, 948-959.

72. Davey Smith G, Shipley MJ, Batty GD, et al. (2000) Physical activity and cause-specific mortality in the Whitehall study. Public Health $114,308-315$.

73. Koba S, Tanaka H, Maruyama C, et al. (2011) Physical activity in the Japan population: association with blood lipid levels and effects in reducing cardiovascular and all-cause mortality. J Atheroscler Thromb $18,833-845$.

74. Ntandou G, Delisle H, Agueh V, et al. (2008) Physical activity and socioeconomic status explain rural-urban differences in obesity: a cross-sectional study in Benin (West Africa). Ecol Food Nutr 47, 313-337.

75. Aderibigbe OR, Pisa PT, Mamabolo RL, et al. (2011) The relationship between indices of iron status and selected anthropometric cardiovascular disease risk markers in an African population: the THUSA study. Cardiovasc J Afr 22, 249-256.

76. Cepeda-Lopez AC, Aeberli I \& Zimmermann MB (2010) Does obesity increase risk for iron deficiency? A review of the literature and the potential mechanisms. Int J Vitam Nutr Res 80, 263-270.

77. Zafon C, Lecube A \& Simo R (2010) Iron in obesity. An ancient micronutrient for a modern disease. Obes Rev 11, 322-328.

78. Motala AA, Esterhuizen T, Pirie FJ, et al. (2011) The prevalence of metabolic syndrome and determination of the optimal waist circumference cutoff points in a rural South African community. Diabetes Care 34, 1032-1037.

79. Gooding HC, Walls CE \& Richmond TK (2011) Food insecurity and increased BMI in young adult women. Obesity (Silver Spring) 20, 1896-1901.

80. Franklin B, Jones A, Love D, et al. (2012) Exploring mediators of food insecurity and obesity: a review of recent literature. J Community Health 37, 253-264.

81. Institut de Recherche pour le Développement (French Research Institute for Delevopment) (2008) Rapport de fin d'enquête: Vulnérabilité alimentaire en milieu Urbain (VAMU) Onagadongou (maidécembre 2008) (Final Report: Food Supply Vulnerability in Urban Area Onagadongon (May-December 2008)). Ouagadougou: Institut de Recherche pour le Développement.

82. Seligman HK, Laraia BA \& Kushel MB (2010) Food insecurity is associated with chronic disease among low-income NHANES participants. J Nutr 140, 304-310.

83. Velasquez-Melendez G, Schlussel MM, Brito AS, et al. (2011) Mild but not light or severe food insecurity is associated with obesity among Brazilian women. J Nutr 141, 898-902. 